\title{
PROYECTO ECOCITY MANUAL PARA EL DISEÑO DE ECOCIUDADES EN EUROPA
}

Coordinadores de la obra.

Philine Gaffron (Universidad de Tecnología de Hamburgo).

Gé Huismans (SenterNovem, Agencia Holandesa para la Sostenibilidad y la Innovación).

Frank Skala (Departamento de Economía y Gestión Ambiental, Universidad de Ciencias Económicas y Administración de Empresas de Viena).

Libro publicado originalmente en inglés con el título "Ecocity Book I. A better place to live". Viena, Facultas Verlags-und Buchhandels AG. 2005.

Edición en español: Bakeaz 2008 Bilbao, España. Volumen 1 y 2.

Comentarios: Gustavo Carrasco Pérez ${ }^{1}$

El Proyecto Ecocity surge en el marco del $5^{\circ}$ Programa de política y actuación en materia de medio ambiente y desarrollo sostenible de la Comisión Europea. Inicialmente el Proyecto Ecocity fue diseñado para generar alternativas de transporte sostenible. Sin embargo, ulteriormente fue ampliando su campo de reflexión y de aplicación hacia la formulación de un programa integral de investigación sobre la sostenibilidad urbana en el continente europeo. El proyecto fue desarrollado entre los años 2002 y 2005; y a principios del año 2006, se publicaron sus resultados en una primera versión en forma de un manual y en idioma inglés, para luego el año 2008, continuar con la edición en inglés de esta publicación, esta vez, del segundo

1 Arquitecto. Académico del Instituto de la Vivienda. Facultad de Arquitectura y Urbanismo. Universidad de Chile. Correo electrónico: gcarrasco@munistgo.cl volumen, así como de su versión en español, la cual ha conservado la misma estructura de las anteriores en idioma inglés.

El Manual, está compuesto por dos volúmenes independientes pero relacionados entre sí. En el primer libro, se exponen los criterios de referencia y el marco conceptual del proyecto, así como sus conclusiones y enseñanzas. También se describen y evalúan con respecto a un mismo patrón de análisis los siete proyectos piloto que el proyecto Ecocity consideró en el planteamiento inicial del mismo. El segundo libro tiene un carácter más técnico y contiene una descripción pormenorizada de las herramientas prácticas que se han empleado en el 
proyecto y cuya utilización se recomienda para el diseño de ecociudades en Europa.

Como se define en el libro primero de este manual, una ecociudad está formada por barrios compactos, pensados para el peatón, con mixtura de usos, e integrado en un sistema urbano mayor, de tipo policéntrico y orientado al transporte público. Esta ecociudad está dotada de espacios públicos de un diseño de calidad, con una adecuada integración de áreas verdes y del patrimonio cultural. De acuerdo al texto, esta propuesta presenta un evidente contraste con las dinámicas que apuntan a la expansión horizontal de las ciudades y la conformación de extensas periferias, en donde el automóvil particular es el medio de transporte hegemónico, con todo lo que aquello implica en términos de consumo de suelo, consumo de combustibles fósiles, incremento en los índices de contaminación y los efectos nocivos que dicha situación genera en la salud de las personas.

El libro segundo contiene algunas directrices generales y específicas concebidas como ayuda para la articulación del planeamiento de una ecociudad, así como información más detallada sobre técnicas de planeamiento, dirigidas, por ejemplo, a facilitar un enfoque integral. Pasa revista también a herramientas de planeamiento tales como el inventario de medidas concretas para el diseño de una ecociudad, orientadas a cada uno de los elementos de planificación, tales como el contexto, la estructura urbana, el transporte, los flujos de energía y materiales y los aspectos socioeconómicos.

Resulta de interés destacar la presentación que hace del libro, la Ministra de la Vivienda de España, Beatriz Corredor Sierra, por los correlatos que pueden hacerse con respecto a los enfoques que sobre estas mismas materias suceden en nuestro medio:

Junto con señalar que los modelos de urbanismo tradicionales resultan hoy en día incapaces de ofrecer respuestas a los problemas sociales, económicos y ambientales de las ciudades; que las ineficiencias que enfrenta el país son grandes, destacando por ejemplo, que "el sector de la construcción acapara más de la mitad de la energía consumida en España, tanto en la edificación como en el uso y mantenimiento de los edificios", que "es una responsabilidad pública el buscar soluciones de sostenibilidad para la nueva ciudad que se rehace y mejora de continuo"; expresa que "la situación económica y ecológica incierta de estos tiempos es un momento adecuado para apostar decididamente por la sostenibilidad en la construcción de ciudades y territorios. Las políticas de vivienda están apostando tanto por la rehabilitación y renovación de barrios como por la eficiencia ambiental de la vivienda nueva y usada. Se trata de favorecer el paso de un modelo de crecimiento urbanístico extensivo a la renovación intensiva de la ciudad, que reduce el 
consumo de suelo y aumenta en forma sustancial la utilización de mano de obra. Por esto el nuevo plan 2009-2012 se denomina Plan Estatal de Vivienda y Rehabilitación".

\section{El volumen I está estructurado en 5 grandes capítulos:}

El primero corresponde a una introducción al Proyecto Ecocity, y a las definiciones de referencia, en el segundo capítulo se aborda la visión de una ecociudad, los objetivos generales y específicos y los elementos de planificación y desarrollo. El tercer capítulo se refiere al proceso de planificación de una ecociudad; el cuarto, a los conceptos para la creación de ecociudades y ecobarrios, tomando para este efecto el ejemplo de las siete ciudades piloto, lo que incluye la descripción de los respectivos "masterplan"; ciudades que se encuentran emplazadas en diversos países europeos; y el capítulo quinto aborda los resultados obtenidos y se pregunta ¿qué hemos aprendido?

El volumen II se plantea cómo hacer realidad una ecociudad. Está estructurado en 6 grandes capítulos o secciones:

El primero corresponde a una Introducción, el segundo se refiere a los beneficios y experiencias derivadas de la planificación de ecociudades, el tercero corresponde a una guía básica, en donde se abordan estrategias generales de planificación para la sostenibilidad urbana, y una guía básica para la planificación de ecociudades a escala barrial; el cuarto capítulo se centra en técnicas de planificación de la ecociudad, el quinto se refiere a los instrumentos de planificación de la ecociudad, instrumentos utilizados por el Proyecto Ecocity y los desarrollados durante el Proyecto Ecocity.

Por último, el sexto capítulo corresponde al resumen.

Los dos volúmenes de este manual, cuentan con planimetrías, esquemas, matrices y gráficos que contribuyen a la mejor comprensión del proyecto.

Como se señala en el prólogo del libro I, la ecociudad es una meta. Un objetivo que apunta a ciudades y barrios que lleguen a ser "un mejor lugar para vivir". Lo anterior implica una evidente voluntad política desde el ámbito de los agentes públicos involucrados y de su capacidad para establecer los mecanismos de participación ciudadana y el involucramiento activo de agentes privados. El desarrollo urbano sostenible se plantea de formas diversas, las cuales se pueden resumir en dos grandes grupos: la adaptación de la ciudad existente mediante intervenciones paulatinas a pequeña escala y la propuesta de nuevas ciudades pensadas y planificadas desde su origen en los postulados definidos por la ecociudad.

El compromiso con los proyectos pilotos de las siete ciudades participantes en el Proyecto Ecocity, llega hasta la formulación del "Masterplan". Los 
proyectos ulteriormente han experimentado sus propias evoluciones de acuerdo a los contextos y situaciones particulares a cada una de ellas.

Al momento de publicarse el libro, las siete ciudades y/o barrios de ciudades existentes se encontraban en situaciones disímiles:

En Bad Ischel (Austria), el proyecto permanecía sólo a nivel de la propuesta o masterplan; en Trinitat Nova (Barcelona), Vuores (Tampere, Finlandia) y Umbertide (Italia), se habían aplicado parcialmente y en diverso grado las recomendaciones del proyecto Ecocity; en Trnava (Eslovaquia) y Györ (Hungría), se habían generado profundos cambios en los planes, en correlato con los acelerados cambios experimentados en ambos países, y finalmente, en Tubinga-Derendingen (Alemania), el ciclo de planificación del proyecto había seguido las fases previstas y se encontraba en etapa de ejecución, en concordancia con las definiciones del plan.

El segundo volumen del manual, remata en una frase decidora, atribuida a Eleanor Roosevelt: "El futuro pertenece a aquellos que creen en la belleza de sus sueños".

Todo un programa.

Gustavo Carrasco Pérez

Académico INVI 